\section{Controversial proposals for reform at Tokyo University}

Tokyo

Moves are afoot for radical reform of the graduate school of Tokyo University, Japan's leading national university. Under a plan put forward by the Faculty of Science, the undergraduate and graduate schools would be fused to create a six-year master's course. But other faculties and institutes connected to the university are resisting the proposal, which some critics say will only enhance the 'elitism' of the university. Behind the dispute lies a struggle for greater independence by the university's research institutes.

The science faculty's plan calls for students to have two years of general education (as at present) followed by four years of specialization leading to a master's degree, instead of the present system of a four-year undergraduate course followed by two years in graduate school. Science faculty members argue that 80 per cent of their students already go on to graduate school, and by fusing the system they will be able to offer a better course. But the faculties of law and economics oppose the plan as most of their students leave university at the undergraduate level.

Akito Arima, vice-president of the university and former dean of the faculty of science, who is one of the prime supporters of the scheme, says that the graduate school has always been treated as an appendix of the undergraduate system, and has been starved of funds and facilities. In contrast, the various science institutes, whose professors also belong to the graduate school, have been comparatively well-treated, he says. The proposed new graduate school is intended to draw in new funds, technical staff and laboratory space for researchers.

But the professors at the university's institutes are suspicious that the scheme is a plot to steal graduate students, their "golden eggs", says Arima. With a sixyear course, they fear that students will tend to stay on in the faculty's laboratories rather than move to the institutes. Professor Michio Oishi of the university's Institute of Applied Microbiology is also concerned that the new scheme may cause the already limited influx of graduate students from other universities and overseas to dry up completely, enhancing the elite characteristics of the university.

Arima dismisses these fears as a "misunderstanding". He says that under his proposal, graduate student intake would be increased by 20 per cent and there would be plenty of graduate students for everyone. And graduate students from other universities and overseas would be able to enter the system at the fourth-year level by taking an examination, just as they do now.

The proposal comes at a time when some of the National Research Institutes for Joint University Use, such as the High Energy Physics Laboratory in Tsukuba, are advocating the establishment of a 'graduate university'. These national institutes are among the best equipped in Japan, but they suffer from a lack of graduate students - the new graduate university would supply their needs. Arima says that his faculty's proposal is not intended to compete with the 'graduate university'.

What is particularly galling is that Tokyo University's research institutes are steadily gaining independence, and are one by one converting to the status of National Research Institutes for Joint
University Use. First to go was the Institute of Space and Astronautical Sciences, and it will be followed by Tokyo Astronomical Observatory and the Institute of Solid State Physics. The proposal to establish a new graduate school seems intended to save the university from break-up.

In March, professors of the science faculty unanimously adopted a resolution to review the graduate school system. Following this decision, the university as a whole decided to request a budget in fiscal year 1988 to investigate the proposal to establish a 'postgraduate-oriented' university. A decision on the budget request must be made by the Ministry of Education, Science and Culture by the end of this year. If the budget request is granted, although small, it will be a symbolic indication that some sort of reform lies ahead. But in Japan, where consensus must be reached, it is unlikely that changes will be as radical as those proposed by the faculty of science.

\title{
Bleak prospects for Hungarian science as research is cut
}

\section{London}

THE Hungarian Ministry of Finance is planning major cuts in the basic research budget, in spite of recent government assurances to the contrary, according to Academician Ivan T. Berend, president of the academy. Speaking on Budapest Radio's main current events programme, 168 Hours, Berend said that the cuts will almost certainly mean some academy institutes and university departments will have to close. He sharply attacked the "ideological concept" prevalent in the Ministry of Finance, which, he said, holds that health, education and research are "not directly productive" sectors of the economy, and represent a burden on the budget which has to be reduced.

During the past eight years, Berend said, Hungary's scientific infrastructure has deteriorated considerably because of lack of resources and of investment funds. Many of the instruments now in use, he said, are almost obsolete. Since 1985, the

\section{Einstein manuscript Washington}

ONE of Albert Einstein's oldest manuscripts on the theory of relativity has been sold to an unidentified bidder at an auction at Sotheby's in New York for \$1.2 million. The 72-page manuscript, written between 1911 and 1912, had been expected to sell for more than $\$ 700,000$ (see Nature 330, 97; 1987). It set a US record as the highest price paid at auction for a manuscript, and set a worldwide record for unillustrated text manuscripts.
Academy of Sciences has been expressing its concern, and, after prolonged negotiations, a national scientific research fund was established in 1985, which allotted 4,000 million forints to basic research for the 1986-90 five-year plan, a net increase of 10 per cent.

The Hungarian economy, however, is facing considerable problems, and in July this year the government introduced major spending cuts. It was announced, however, that in distributing such funds as were available, priority would be given to the research, health and education sectors. Only a few weeks ago, Berend said, the academy and other research institutions, including the universities, were given guarantees that their funding would not be significantly affected. Although some money would have to be "siphoned off" in 1987, it would be made up to them in the future, and, furthermore, the real value of the 1988 research budget would be maintained. But the new cuts, Berent said, will amount to a 30 per cent reduction over 1987-88, and, in view of previous government assurances, the academy and research institutes were left without contingency plans.

The Academy of Sciences has 36 research institutes, employing almost 3,000 researchers. It is also partially responsible for the financial support of 80 university departments. Cuts on the scale proposed by the Ministry of Finance will make it impossible to maintain this research network, Berend said, as across-the-board cuts would mean that everyone would be left with insufficient funds to function properly.

Vera Rich 